\title{
Algoritmo genético aplicado ao problema de roteamento de veículos: problema do caixeiro viajante no setor varejista
}

\section{Genetic algorithm applied to vehicle route problem: traveler officer problem in retailer sector}

\author{
1 Wellington Gonçalves wellington.goncalves@ufes.br \\ 1 Matheus Sales Oliveira \\ 2 Alessandro Roberto Rocha
}

\footnotetext{
1 Departamento de Engenharias e Tecnologia - Universidade Federal do Espírito Santo

2 Programa de Póis-Graduação em Gestão Pública - Mestrado em Gestão Pública - Universidade Federal do Espírito Santo
}

\section{Resumo}

Problemas de otimização têm como foco principal encontrar uma solução viável entre alternativas possíveis. O Traveling Salesman Problem (TSP) pertence a essa classe de problemas. No entanto, devido à existência de uma variada pluraridade de dimensões e variáveis, as quais compõe o TSP, não é possível encontrar sua solução viável em um tempo polinomial definido. $E$ é por isso que é considerado um dos problemas difíceis de NP-hard. Por esses motivos, apresentamos proposta de um Genetic Algorithm (GA) híbrido para resolução do Traveling Salesman Problem (TSP), no qual o operador de crossover é empregado em uma aplicação local. Essa aplicação obteve soluções adequadas para um ambiente urbano, com um tempo computacional aceitável para o TSP, integrando o GA e as condições ambientais locais. Os resultados experimentais ilustram que a proposta apresentada, além de atender às condicionantes locais da unidade de pesquisa, também, pode ser utilizada em outras situações, sendo parametrizável e adaptável a outros algoritmos genéticos, fornecendo, com isso, precisão e eficiência satisfatória no processamento real da otimização.

\section{Palavras-chave}

Cadeia de suprimentos. Localização de facilidades. Heurística. Gestão adaptativa da diversidade populacional. Solução ideal.

\begin{abstract}
Optimization problems are primarily focused on finding a viable solution among possible alternatives. Traveling Salesman Problem (TSP) belongs to this class of problems. However, due to the existence of a varied plurality of dimensions and variables, which make up the TSP, it is not possible to find its viable solution in a defined polynomial time. And that is why it is considered one of the difficult problems of NP-hard. For these reasons, we present a proposal for a Genetic Algorithm (GA) hybrid for Traveling Salesman Problem (TSP) resolution, in which the crossover operator is employed in a local application. This application obtained solutions suitable for an urban environment, with an acceptable computational time for TSP, integrating GA and local environmental conditions. The experimental results illustrate that the proposal presented, besides meeting the local constraints of the research unit, can also be used in other situations, being parameterizable and adaptable to other genetic algorithms, thus providing satisfactory precision and efficiency in the actual optimization processing.
\end{abstract}

\section{Keywords}

Supply chain. Location of facilities. Heuristic. Adaptive management of population diversity. Ideal solution.

\section{Como você deve citar?}

GONÇALVES, Wellington; OLIVEIRA, Matheus Sales; ROCHA, Alessandro Roberto. Algoritmo genético aplicado ao problema de roteamento de veículos: problema do caixeiro viajante no setor varejista. Cadernos UniFOA, Volta Redonda, n. 43, p. 11-23, agosto, 2020. 


\section{INTRODUÇÃO}

O aumento populacional em meio urbano nos últimos anos tem demandado melhor eficiência e eficácia dos processos de urbanização nas cidades. Embora esse fato seja conhecido por gestores dos setores público e privado, segundo Handy et al. (2002) e Boarnet et al. (2017), é um problema que envolve diversas dimensões e variáveis, as quais interagem entre si, tendo ainda a intervenção de stakeholders.

Dentro desse contexto, o transporte urbano é um importante elemento operacional que interfere diretamente na mobilidade das cidades (CLEOPHAS et al., 2019). Por esse motivo, Guerra (2016) aponta que o planejamento do transporte urbano assume posição de destaque para apoiar requisitos que viabilizam a mobilidade de passageiros e mercadorias em áreas urbanas.

Cidades são locais de lazer, moradia e produção (bens e serviços), além de possuírem polos de consumo e distribuição, os quais também são variáveis geradoras de fluxo de trânsito (KAMARGIANNI et al., 2016). E, nessas circunstâncias, o problema de roteamento de veículos (Vehicle Routing Problem - VRP), por envolver o sistema de transporte urbano, está ligado diretamente à forma urbana e à estrutura espacial (LAPORTE, 1992). Por outro lado, Varun Kumar e Panneerselvam (2017) destacam que a resolução do VRP clássico, por conter diversas rotas de veículo com origens e destinos finais distintos, e conjuntos de clientes com demandas conhecidas, envolve um elevado número de inteirações. No entanto, esses autores enfatizam que, para resolver esses tipos de problemas NP-Hard (Non-deterministic Polynomial-time Hardness), são necessárias heurísticas sofisticadas como Genetic Algorithms (GA).

Assim, considerando os pressupostos dessa seção e também que o problema do caixeiro viajante (DANTZIG; RAMSER, 1959) pode ser aplicado a diversos cenários de resolução do VRP, neste trabalho, foi utilizada a heurística de GA para estimar o caminho a ser percorrido por um representante comercial. Para tanto, o GA foi implementado em MATLAB® (MATrix LABoratory), sendo utilizada a linguagem Python em conjunto com a Google Maps JavaScript API para gerar os mapas com as rotas encontradas.

\section{TRANSPORTE URBANO SUSTENTÁVEL}

\subsection{Mobilidade urbana e a distribuição de cargas fracionadas}

Áreas urbanas são cenários complexos em que a mobilidade de passageiros e mercadorias ocorre de maneira simultânea (RODRIGUE et al., 2016). E, em diversos casos, Rodrigue et al. (2016) afırmam que os movimentos de passageiros e mercadorias são intimamente complementares, mas, às vezes, podem estar competindo pelos usuários, em termos de uso das infraestruturas terrestres e de transporte disponíveis.

Dentro desse contexto, a mobilidade urbana é vista por Mäkinen et al. (2015) como sendo o principal ponto a ser trabalhado, quando o assunto é prever possíveis trajetórias dentro das cidades. Dessa forma, as características de uso da terra e a organização estrutural de áreas urbanas influenciam diretamente a oferta e o desenvolvimento de serviços de transporte (STIGLIC et al., 2018).

O Brasil, nas últimas décadas, se firmou como um país essencialmente urbano e metropolitano (IPEA, 2016). Essa visão é sustentada devido a $84 \%$ da população brasileira viver em cidades, sendo que $47 \%$ dessa população está em regiões metropolitanas (IBGE, 2010). Em decorrência disso, de acordo com Stiglic et al. (2018), questões relacionadas à operacionalidade das cidades, como, por exemplo, seus problemas e desafios, têm alavancado cada vez mais destaque em debate sobre políticas públicas voltadas ao desenvolvimento. Essa discussão em território brasileiro foi ainda alavancada por meio da 
Lei Federal n 12.587/2012, conhecida como "Lei da mobilidade", a qual define princípios e diretrizes acerca de direcionamentos que impulsionam a sustentabilidade, acessibilidade e mobilidade urbana (BRASIL, 2012).

O transporte urbano de mercadorias é responsável por atender à cadeia de consumo das cidades, sendo essencial no desenvolvimento delas, apesar dos conflitos e problemas advindos da atividade (OLIVEIRA et al., 2016). Diante disso, para Martorelli et al. (2019), o planejamento de deslocamentos nas cidades é o principal responsável para a adequada distribuição de cargas e mercadorias em centros urbanos.

\subsection{Traveling salesman problem (TSP)}

A globalização, o comércio e o transporte de mercadorias estão intimamente inter-relacionados e dizem respeito a uma escala de mobilidade que abrange cidades, nações e frequentemente continentes (RODRIGUE et al., 2016). No entanto, embora essa mobilidade transnacional esteja sujeita a diversas considerações geopolíticas, de acordo com Murray e Chu (2015), é necessário que se considere prioritariamente o roteamento de veículos como parte da solução logística da distribuição de cargas e mercadorias.

Entretanto, segundo Veenstra et al. (2017), quando se trata de carga fracionada, é importante que se tenha soluções que se enquadrem às particularidades dos clientes. Em face disso, Dorigo e Gambardella (1997) apresentam o Traveling Salesman Problem (TSP) ou Problema do caixeiro-viajante como solução factível a problemas que envolvam cargas fracionadas ou em pequenas quantidades a serem transportadas.

Dantzig e Ramser (1959) propuseram, pioneiramente, uma resolução ao TSP em que consideram um grafo $G(V, A)$ qualquer para descrever o TSP, sendo $V$ o conjunto de nós e, $A$ um conjunto de arcos que liga cada nó (Figura 1). Esses autores ainda descrevem que os nós representam os pontos de origem/destino e os arcos são os pares ordenados desses pontos, que correspondem ao caminho possível para realizar o trajeto. Dessa forma, a solução do TSP consiste em identificar uma rota que inicie e termine no mesmo ponto de origem, sendo conhecidas as distâncias entre ponto de um dado grafo, passando por todos os pontos uma única vez, formando um circuito hamiltoniano de menor custo (ELGESEM et al., 2018).

Figura 1 - Formulação clássica do TSP

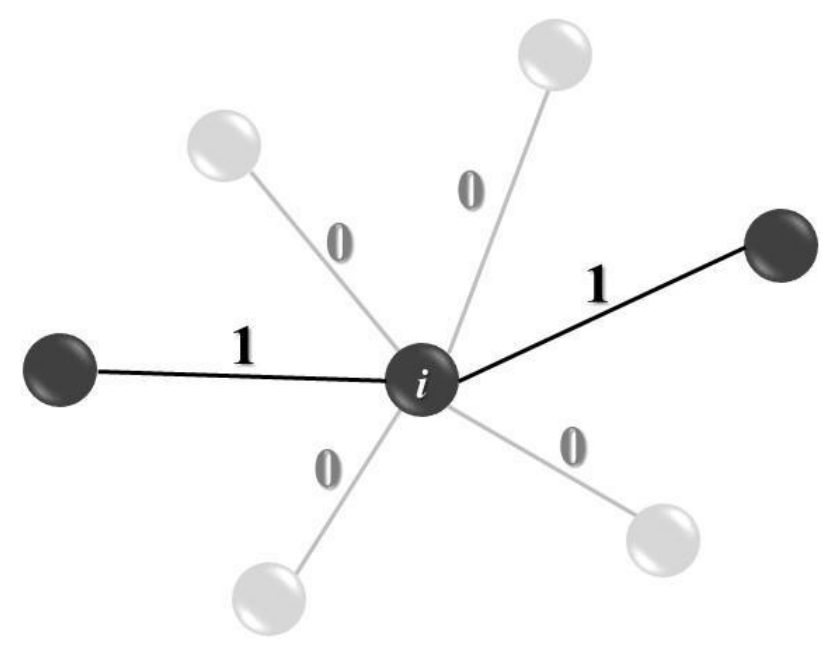

Fonte: Baseado em Dantzig e Ramser (1959). 
A modelagem matemática do TSP, proposta por Dantzig e Ramser (1959), analisa as condições de solicitação de cada nó de um dado grafo. E, a partir disso, esses autores formularam sua versão do Traveling Salesman Problem, considerando ser esta uma variação do Vehicle Routing Problem, além de um problema de otimização pertencente à classe NP-Hard, propondo da seguinte forma (Equações $1,2,3,4,5$ e 6$)$ :

$$
\left\{\begin{array}{l}
x_{i j}=1, \text { se for percorrido o arco de } i \text { até } j ; \\
x_{i j}=0, \text { caso contrário }
\end{array}\right.
$$

$$
\operatorname{Min} \cdot \sum_{i=1}^{n} \sum_{j=1}^{n} c_{i j} x_{i j}
$$

Sujeito a:

$$
\begin{aligned}
& \sum_{j=1}^{n} x_{i j}=1, \forall i=1,2, \ldots, n \\
& \sum_{i=1}^{n} x_{i j}=1, \forall j=1,2, \ldots, n
\end{aligned}
$$

$$
\sum_{i \in V} \sum_{j \in V} x_{i j} \leq|V|-1, \forall V \subset A: 1<|V|<n-1
$$

$$
x_{i j} \in\{0,1\}
$$

Desse modo, para operacionalizar a resolução do Traveling Salesman Problem (TSP), Dantzig e Ramser (1959) consideram, nas Equações de 1 a 6, que o sistema (1) representa a variável binária $x_{i j}$ para cada arco $(i, j)$ e seu valor é limitado pela restrição (6). Da mesma forma, considerando, $c_{i j}$ um índice qualquer associado ao arco $(i, j)$, a função objetivo (2) representa o somatório dos índices de todo o percurso e possui a característica de minimizar esse índice total. A restrição (3) garante que do vértice $i$ sai apenas um arco para qualquer vértice $j$; a restrição (4) garante que o vértice $j$ é acessado por apenas um arco vindo de qualquer vértice $i$; temos assim, a garantia de que o viajante passa por todos os vértices uma só vez. A restrição (5) garante que a solução contenha um único ciclo que cobre todos os vértices, sem repetições.

\subsection{Algoritmos genéticos para resolução do problema do caixeiro viajante}

As características e tendências de comportamento dos meios urbanos, assim como os stakeholders que os compõem, estão em constante mutação. E isso se deve à ação de inúmeras dimensões e variáveis, que se inter-relacionam no universo urbano, as quais, também, influenciam comportamentos e tendências nas mais variadas circunstâncias e setores (DIBBLE et al., 2019). Dentro desse contexto, Laporte (1992) e, Braekers et al. (2016) destacam que o problema de roteamento de veículos em meio urbano, devido à mutação urbana, demanda soluções que possam ser implementadas e parametrizadas por diferentes realidades operacionais.

Existem inúmeras heurísticas e meta-heurísticas na literatura que são dedicadas à resolução de problemas de roteamento de veículos (OYOLA et al., 2018; SCHIFFER et al., 2019). No entanto, devido 
ao elevado número de alternativas às diversas situações, é necessário que, ao selecionar uma dada aplicação, ela se adeque não somente a apresentar um resultado matemático, mas também permita adaptar a abordagem estocástica (JUNEJA et al., 2019).

Dessa forma e, considerando as particularidades e limitações de investimentos do setor varejista brasileiro, neste trabalho, foi selecionada a utilização de algoritmos genéticos para auxiliar na resolução do problema do Caixeiro Viajante. Por outro lado, Karakatič e Podgorelec (2015) recomendam utilizar algoritmos genéticos para encontrar soluções para problemas de roteamento de veículos em menos tempo. Esses autores ainda afirmam que é uma das características dessas heurísticas e meta-heurísticas, que inclusive se baseiam na imitação do processo natural da evolução.

Para Holland (1992), algoritmos genéticos são abordagens estocásticas baseadas em processos evolutivos biológicos e, por isso, são métodos de otimização inspirados na evolução. Na opinião desse autor, isso se justifica a partir do entendimento de que, enquanto na natureza indivíduos que são saudáveis possuem elevadas chances de sobrevivência e de acasalamento, a geração subsequente tende ser mais evoluída do que a anterior. $O$ trabalho de Holland (1992) apresenta um algoritmo inspirado na teoria da seleção natural, em nove etapas (Figura 2), em que este atua sobre uma população de indivíduos, aumentando as chances de sobrevivência dos mais aptos geneticamente e, a partir disso, produz indivíduos cada vez melhores, suprimindo os menos aptos.

Figura 2 - Síntese da operacionalização de algoritmo genético

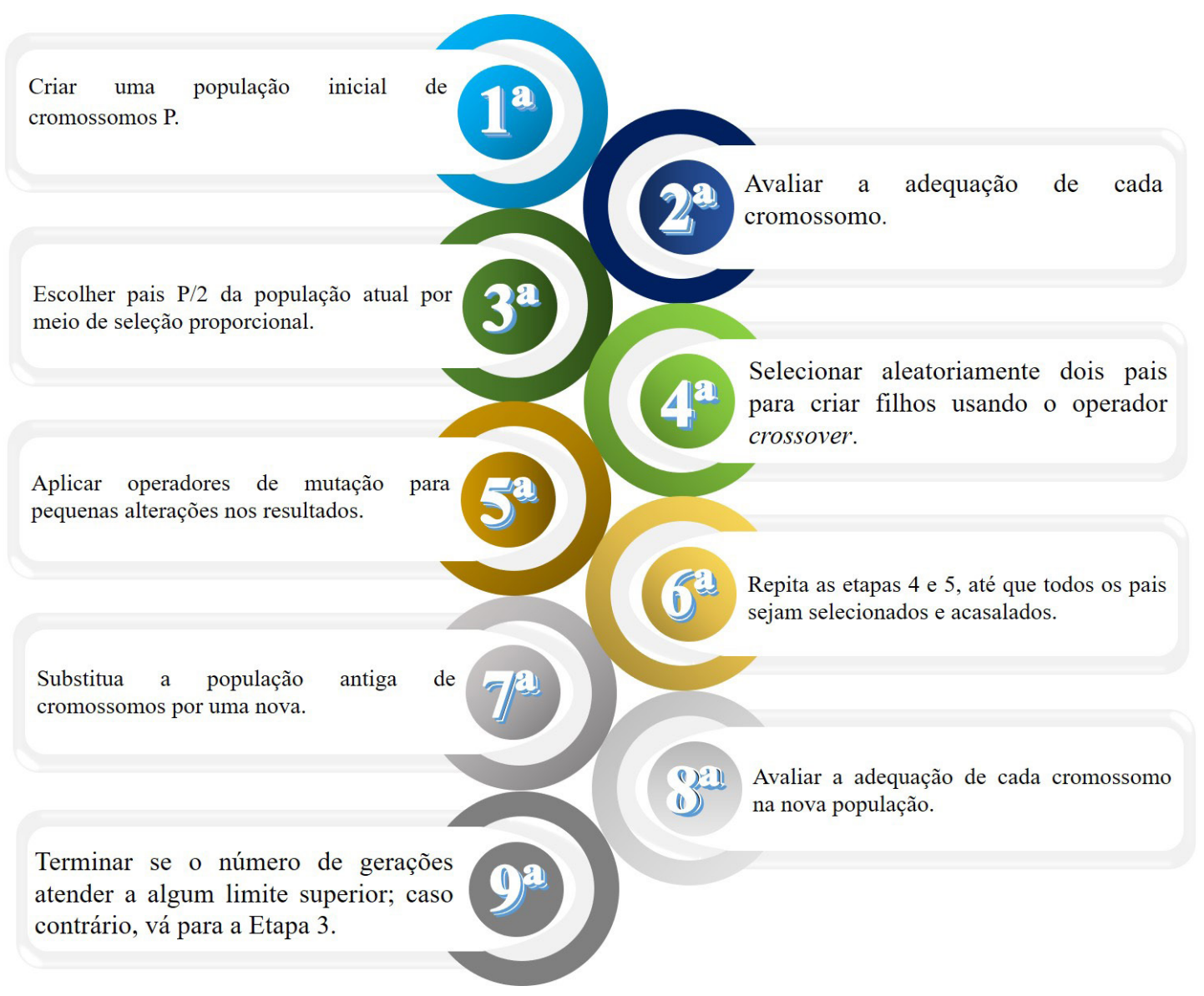

Fonte: Adaptado de Holland (1992). 
Nos últimos anos, o emprego da Inteligência Artificial como ferramenta de gestão para auxílio à tomada de decisão e resolução de problemas complexos de roteamento de veículos se tornou cada vez mais frequente. De acordo com Osaba et al. (2016), esse fenômeno por ser explicado devido à complexidade e inteirações de diversas dimensões e variáveis, que também interagem entre si e que 0 mundo moderno impõe a sociedade.

Para Silva (2017), além da amplitude de soluções de algoritmos genéticos aplicados a problemas de caixeiro viajante, existem variações dessas soluções que podem ser parametrizadas de acordo com a conveniência e necessidades de resolução do problema de roteamento.

\section{ABORDAGEM METODOLÓGICA E DESENVOLVIMENTO DA PESQUISA}

A condução do desenvolvimento da pesquisa teve por princípio base uma abordagem metodológica que possa ser replicada por empresas de diversos setores, órgãos públicos, profissionais ligados ao setor, pesquisadores e estudantes interessados no tema. A partir dessa premissa, foi selecionada, como unidade de pesquisa, uma Empresa de Pequeno Porte (EPP) do ramo de representação comercial de agronegócio e alimentos, sediada no município de Linhares, com atuação em todo o Estado do Espírito Santo (Brasil). De tal modo, as verificações transcorreram no sentido de diagnosticar e cooperar com a otimização da operacionalização do setor de distribuição dessa EPP.

Inicialmente, foi realizado um diagnóstico para mapeamento e caracterização de localidades a serem atendidas. Na sequência, foi elaborada uma proposição de solução do TSP, utilizando-se algoritmo genético, implementado em MATLAB®. Essa proposição considerou como parâmetros de entrada: matriz de distâncias; posição de cada cidade no mapa gráfico do MATLAB®; taxa de mutação; taxa de recombinação; números de genes a serem recombinados; tamanho da população e o número de gerações (critério de parada).

Dessa forma, para realização dessa implementação no MATLAB® (Figura 1), foram seguidos os pressupostos indicados por Holland (1992) - Figura 2 e, a partir disso, a operacionalização foi realizada por meio de 7 passos. O primeiro gerou uma população inicial de tamanho $N$, a qual é informada no início da execução. Na primeira geração, essa população é criada de forma aleatória. Para iniciar a execução do algoritmo, é utilizado um conjunto de soluções-padrão (em formato aleatório), em que o atendimento a todos os pontos inicia na origem e retorna a ela.

No segundo passo, foi feita a recombinação genética (crossover), a fim de gerar descendentes para a próxima geração. 0 procedimento inicial desse passo começa com a seleção aleatória de cinco indivíduos da população e, em seguida, é realizado um torneio nesse subconjunto, em que os melhores indivíduos são escolhidos para a reprodução. Após essas realizações, são selecionados os genes que serão recombinados, e, por fim, são gerados os filhos com os genes modificados. Todo o processo é repetido até que sejam gerados $n:\left(T_{\text {pop. }} \times T_{\text {rec. }}\right)$ filhos, desde que uma solução satisfatória seja encontrada, em que: $T_{p o p}$ é o tamanho da população e, $T_{r e c}$ é a taxa de recombinação.

Prosseguindo, foi realizado o processo de mutação, momento em que são efetuadas pequenas modificações nos genes de um indivíduo da população ( $3^{\circ}$ passo). Inicialmente, são selecionados os genes que sofreram mutação e, após essas seleções, são gerados os indivíduos com mutação, sendo esse processo repetido até que sejam gerados $m:\left(T_{p o p .} \times T_{m u t .}\right)$ filhos, em que: $T_{m u t .}$ é a taxa de mutação. 
O quarto passo de iteração selecionou indivíduos de melhor procedência para a criação de nova população. Essa seleção ocorreu por meio da consideração da seguinte formulação: $\left(T_{\text {pop. }}-\left(T_{\text {pop. }} \times T_{\text {mut. }}\right)-\left(T_{\text {pop. }} \times T_{\text {rec. }}\right)\right)$, a qual seleciona esses indivíduos na população anterior e, posteriormente, cria uma nova população composta por aqueles de melhor procedência, os recombinados e os que sofreram mutação. Assim, ao final de cada geração ( $5^{\circ}$ passo), o mapa das cidades é atualizado contendo a rota da melhor solução encontrada na população. Após isso, é necessário repetir os passos de 2 a 5 até que a quantidade de gerações seja alcançada ( $6^{\circ}$ passo), sendo este o critério de parada. Ao final da execução do algoritmo genético, é gerado um arquivo de saída contendo a melhor solução encontrada. A partir desse arquivo foi criado um algoritmo na linguagem Python 3.8 e a Maps JavaScript $A P I$ version 3.33 para exibição da rota a ser percorrida.

\section{RESULTADOS}

A modelagem do TSP foi iniciada com um diagnóstico na unidade de pesquisa que identificou a rota com elevado número de demanda e também complicações no estabelecimento da sequência ideal para atendimento, considerando as distâncias a serem percorridas. Assim, após esse diagnóstico, foi possível formular um conjunto de cidades a serem visitadas, quais sejam: (1) Vitória - origem e destino final; (2) Guarapari; (3) Cachoeiro de Itapemirim; (4) Linhares; (5) Colatina; (6) Aracruz; (7) São Mateus; (8) Nova Venécia; (9) São Gabriel da Palha e; (10) Alegre, considerando que cada cidade deve ser visitada apenas uma vez.

Na sequência, foram investigadas as distâncias Euclidianas (distâncias métricas) entre os pontos (cidades) a serem atendidos (Tabela 1), sendo elas obtidas por intermédio do Google Earth ${ }^{\circledR}$ software - version 7.3 (GOOGLE INC., 2019). No entanto, devido às distorções naturais do planeta e também de erros de aproximação e mensuração, um fator de ajuste no valor de 1,23, calculado a partir da média entre as distâncias dos estabelecimentos a serem atendidos, e o retorno ao ponto inicial, foi adicionado a essas distâncias (GONÇALVES et al., 2014).

Tabela 1 - Matriz de distâncias ajustadas (Km)

\begin{tabular}{ccccccccccc}
\hline & $\mathbf{1}$ & $\mathbf{2}$ & $\mathbf{3}$ & $\mathbf{4}$ & $\mathbf{5}$ & $\mathbf{6}$ & $\mathbf{7}$ & $\mathbf{8}$ & $\mathbf{9}$ & $\mathbf{1 0}$ \\
\hline $\mathbf{1}$ & 0 & 59 & 138 & 131 & 131 & 79 & 214 & 246 & 202 & 201 \\
\hline $\mathbf{2}$ & 59 & 0 & 91 & 194 & 188 & 141 & 276 & 309 & 264 & 155 \\
\hline $\mathbf{3}$ & 138 & 91 & 0 & 271 & 271 & 219 & 353 & 386 & 342 & 61 \\
\hline $\mathbf{4}$ & 131 & 194 & 271 & 0 & 74 & 60 & 82 & 120 & 110 & 335 \\
\hline $\mathbf{5}$ & 131 & 188 & 271 & 74 & 0 & 77 & 155 & 123 & 79 & 260 \\
\hline $\mathbf{6}$ & 79 & 141 & 219 & 60 & 77 & 0 & 142 & 180 & 148 & 282 \\
\hline $\mathbf{7}$ & 214 & 276 & 353 & 82 & 155 & 142 & 0 & 67 & 110 & 417 \\
\hline $\mathbf{8}$ & 246 & 309 & 386 & 120 & 123 & 180 & 67 & 0 & 44 & 390 \\
\hline $\mathbf{9}$ & 202 & 264 & 342 & 110 & 79 & 148 & 110 & 44 & 0 & 345 \\
\hline $\mathbf{1 0}$ & 201 & 155 & 61 & 335 & 260 & 282 & 417 & 390 & 345 & 0 \\
\hline
\end{tabular}

Fonte: Autores (2020).

Assim, a partir dessa matriz (Tabela 1), foi elaborado, no MATLAB®, o mapa das localizações das cidades a serem visitadas (Figura 3), contendo proposição inicial de rota entre elas, utilizando-se

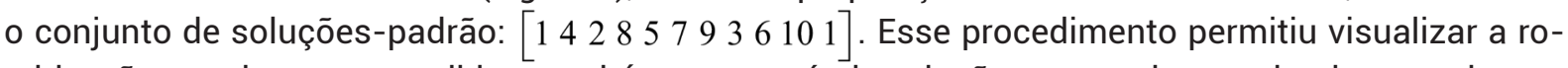
teirização que deve ser atendida e também em possíveis soluções que podem ser implementadas, as quais são baseadas na expertise dos gestores da EPP e do motorista da empresa. 
Figura 3 - Modelo gráfico do conjunto de soluções inicial (Km)

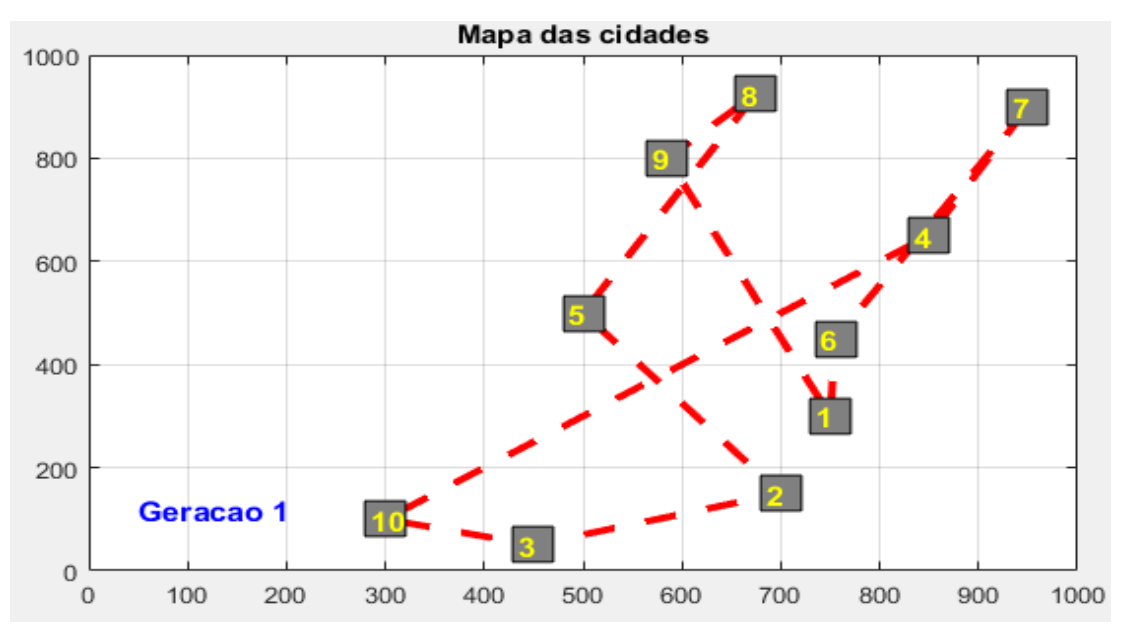

Fonte: Autores (2020).

Posteriormente, foram realizados testes de cenários utilizando-se a proposição de solução do TSP, por intermédio de GA implementado em MATLAB®, o qual considerou, além da matriz de distâncias (Tabela 1) e do mapa de posicionamento de cada cidade (Figura 3), um conjunto de parâmetros de entrada otimizado (Figura 4).

Figura 4 - Configuração inicial de parâmetros de entrada

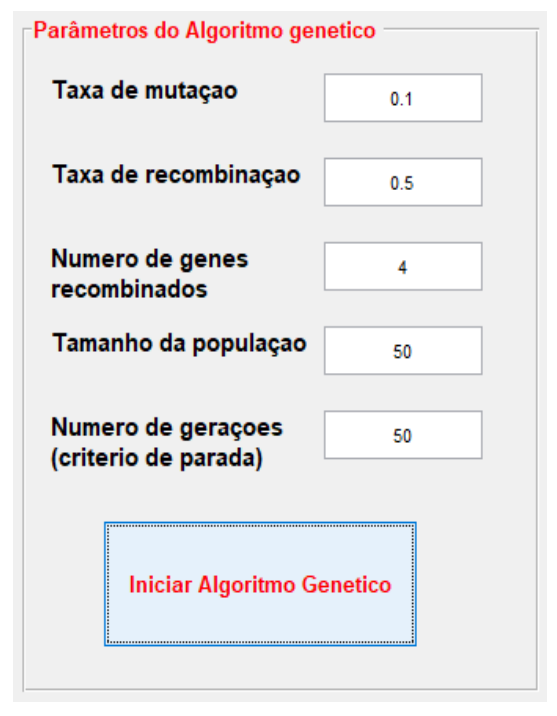

Fonte: Autores (2020).

A partir dessa configuração (Figura 4), a solução ótima encontrada pelo algoritmo genético teve custo mínimo com percurso de $882 \mathrm{Km}$ (Figura 5), após a realização de 50 gerações, tendo como origem Vitória, com a seguinte sequência de rota: Aracruz; Linhares; São Mateus; Nova Venécia; São Gabriel da Palha; Colatina; Alegre; Cachoeiro de Itapemirim; Guarapari e; ao final, retorno à origem. 
Figura 5 - Representação gráfica da solução ótima (Km)

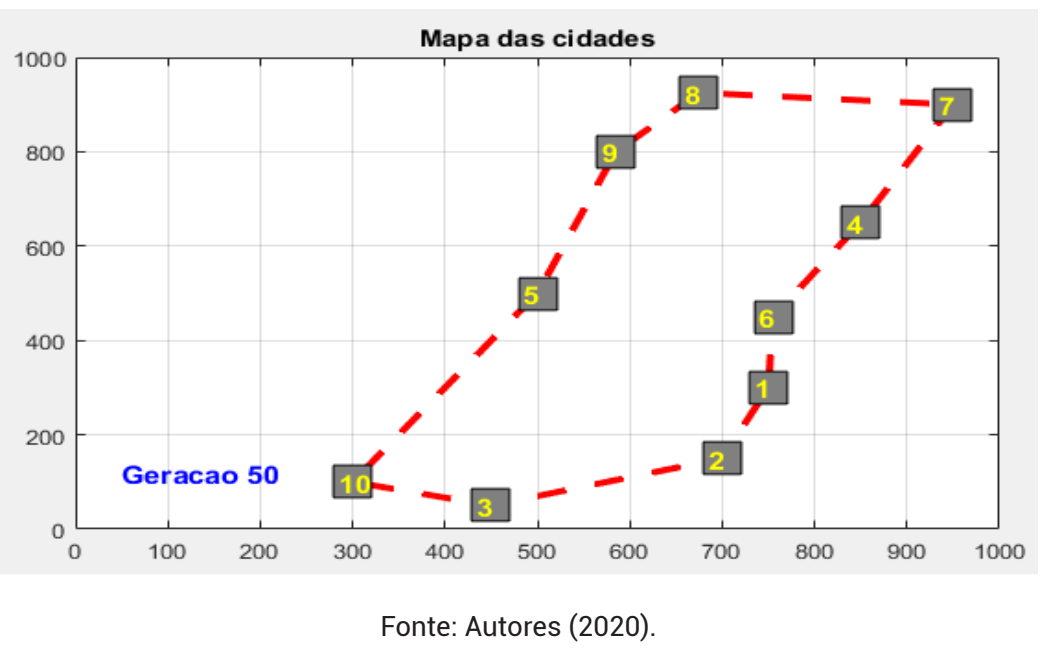

Prosseguindo, após a obtenção da solução ótima obtida no MATLAB®, foi executado o GA na linguagem Python 3.8, empregando-se concomitantemente a Maps JavaScript API version 3.33 para plotagem da rota a ser percorrida no Google Maps (Figura 6), sendo que a linha na cor azul representa a rota; o marcador na cor vermelho, a cidade em que está localizada a origem e; os marcadores em azul, as demais cidades a serem visitadas.

Figura 6 - Roteirização a partir do Maps JavaScript API

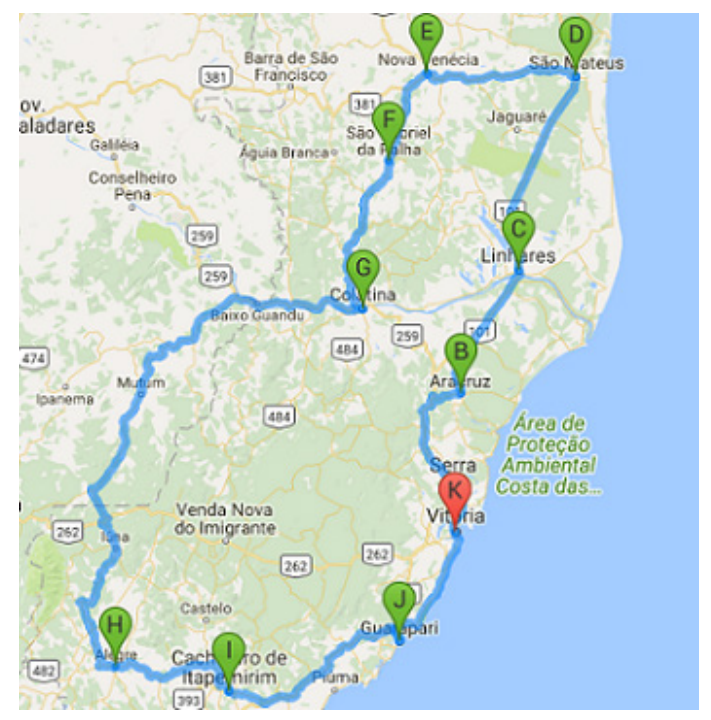

Fonte: Autores (2020).

No entanto, é importante observar que essa implementação concomitante com a API obteve um custo mínimo obtido com um percurso de $895 \mathrm{Km}$. E, embora esse resultado seja superior ao encontrado pelo GA, vale ressaltar que a Maps JavaScript API considera as condições locais de fluxo do trânsito, como também o tempo estimado da rota a partir dessas condições. 0 acréscimo de percurso ocorre no trecho entre as cidades de Colatina e Alegre, em que, apesar da opção pelo caminho mais curto, o tempo total de viagem obtido pela API é superior, fato que, consequentemente, leva à escolha por uma rota mais extensa, porém com o custo relacionado ao tempo menor. 
Além do mapa com a roteirização, outra significativa disponibilização de informação que a API fornece está na descrição da composição de rotas a serem seguidas em cada trajeto, especificando distâncias, direções e sentidos nas ruas, avenidas e rodovias a serem percorridas (Figura 7), sendo um item relevante para realização de novos planejamentos e reconfigurações que se façam necessários em campo.

Figura 7 - Segmento de rota obtido por meio do Maps JavaScript API

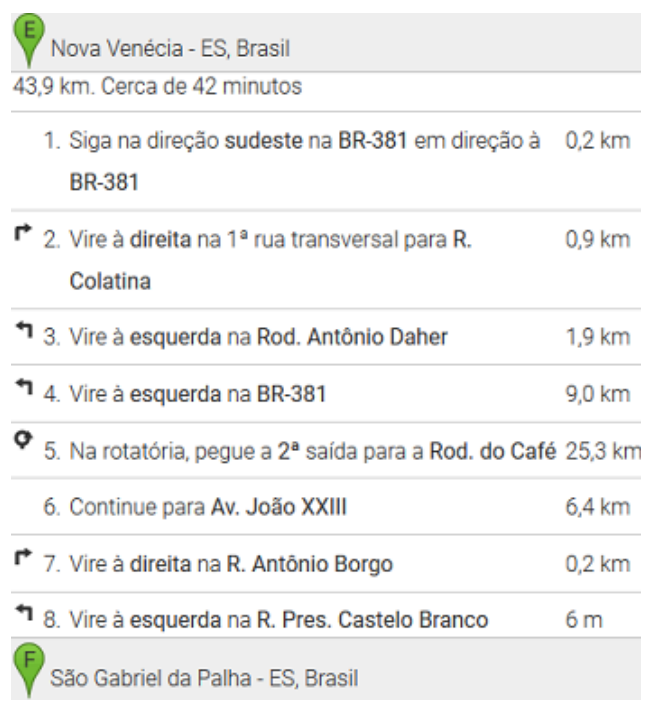

Fonte: Autores (2020).

\section{CONSIDERAÇÕES FINAIS}

Este trabalho contribui para a literatura, apresentando uma abordagem heurística para o TSP que emprega uma combinação de recursos (Google Earth ${ }^{\circledR}$ software, algoritmo genético, MATLAB ${ }^{\circledR}$ e linguagem Python). Nossa abordagem, além de encontrar soluções ideais para casos distintos do cotidiano, como verificado na aplicação junto à unidade de pesquisa, contribui também para minimização de custos e atividades comerciais de MEI (Micro Empreendendor Individual), Microempresa (ME) e Empresa de Pequeno Porte (EPP), devido ao baixo custo de utilização.

Abordamos o TSP utilizando GA e também admitindo que metas e condições ambientais para tráfego mudam suas condições com o decorrer do tempo. Por esse motivo, outra importante contribuição deste trabalho está na maneira de resolução do problema de otimização de rota dinâmica, empregando-se uma abordagem de previsão que, ao combinar GA e outros recursos, permite ao algoritmo implementado sugerir uma roteirização quase ideal.

Assim, os resultados obtidos também permitem concluir que, embora haja diferentes condições de fluxo de trânsito no meio urbano, com diferentes velocidades, locais específicos para carga e descarga, além de janelas de tempo, dentre outras condicionantes, a distância que efetivamente é percorrida, representa economias consideráveis ao custo total (combustível, manutenção, depreciação, tempo de circulação, seguros, etc.).

Vale ressaltar que, devido à dinamicidade de operacionalização da abordagem proposta, considerando seu tempo total de execução, é admissível que novas rotas sejam recalculadas de forma a não interferir na operacionalização de entregas. Esse procedimento também se aplica em casos que haja 
necessidade de verificar novas roteirizações em tempo real. Além disso, essa abordagem proporciona condições variadas de aplicações e, com isso, nossa solução pode ser empregada de forma genérica, flexível e adaptável, reservando suas limitações de utilização, como, por exemplo, o acesso à internet, em cenários de planejamento e operações que possuam diferentes condições para atuação em campo (situações estáticas, dinâmicas ou mistas).

A comparação da implementação do TSP com as soluções obtidas é suficiente para provar que a heurística proposta é promissora. Para estudos futuros, o uso de algoritmos genéticos a partir da abordagem apresentada neste trabalho pode ser executada em paralelo para aplicações em tempo real. Além disso, a operacionalização dessa abordagem pode ser aplicada a outras variações de problemas do TSP, tais como: Maximum Traveling Salesman Problem (MTSP), Symmetric Traveling Salesman Problem (STSP) e Asymmetric Traveling Salesman Problem (ATSP), e, a partir disso, ampliar formas de procedimentos para encontrar soluções com eficiência para cada caso em particular.

\section{AGRADECIMENTOS}

Agradecemos ao Laboratório de Pesquisa Operacional, Logística e Transporte (POLT) da Universidade Federal do Espírito Santo (UFES) / Centro Universitário Norte do Espírito Santo (CEUNES), pelo apoio acadêmico e técnico na concepção e desenvolvimento deste trabalho. E também à Fundação de Amparo à Pesquisa e Inovação do Espírito Santo, por meio dos Editais FAPES-CNPq 13/2018 - PICJr e, FAPES 21/2018 - Universal.

\section{REFERÊNCIAS}

BOARNET, M. G.; GIULIANO, G.; HOU, Y.; SHIN, E. J. First/last mile transit access as an equity planning issue. Transportation Research Part A: Policy and Practice, v. 103, p. 296-310, 2017.

BRAEKERS, K.; RAMAEKERS, K.; VAN NIEUWENHUYSE, I. The vehicle routing problem: State of the art classification and review. Computers \& Industrial Engineering, v. 99, p. 300-313, 2016.

BRASIL. Lei no 12.587, de 3 de janeiro de 2012. Institui as diretrizes da Política Nacional de Mobilidade Urbana. Diário Oficial [da] República Federativa do Brasil: seção 1, Brasília, DF, seção 1, p. 1, 4 jan. 2012.

CLEOPHAS, C.; COTTRILL, C.; EHMKE, J. F.; TIERNEY, K. Collaborative urban transportation: recent advances in theory and practice. European Journal of Operational Research, v. 273, n. 3, p. 801-816, 2019.

DANTZIG, G. B.; RAMSER, J. H. The truck dispatching problem. Management Science, v. 6, n. 1, p. 80-91, 1959.

DIBBLE, J.; PRELORENDJOS, A.; ROMICE, O.; ZANELLA, M.; STRANO, E.; PAGEL, M.; PORTA, S. On the origin of spaces: Morphometric foundations of urban form evolution. Environment and Planning B: Urban Analytics and City Science, v. 46, n. 4, p. 707-730, 2019.

DORIGO, M.; GAMBARDELLA, L. M. Ant colony system: A cooperative learning approach to the traveling salesman problem. Transactions on Evolutionary Computation, v. 1, n. 1, p. 53-66, 1997.

ELGESEM, A. S.; SKOGEN, E. S.; WANG, X.; FAGERHOLT, K. A traveling salesman problem with pickups and deliveries and stochastic travel times: An application from chemical shipping. European Journal of Operational Research, v. 269, n. 3, p. 844-859, 2018. 
GONÇALVES, D. N. S.; GONÇALVES, C. M.; ASSIS, T. F.; SILVA, M. A. Analysis of the difference between the euclidean distance and the actual road distance in Brazil. Transportation Research Procedia, v. 3, p. 876-885, 2014.

GOOGLE INC. Company Information. Google Earth®. Disponível em: http://www.google.com.br/intl/ pt-BR/earth. Acesso em: 24 maio 2019.

GUERRA, E. Planning for cars that drive themselves: Metropolitan planning organizations, regional transportation plans, and autonomous vehicles. Journal of Planning Education and Research, v. 36, n. 2, p. 210-224, 2016.

HANDY, S. L.; BOARNET, M. G.; EWING, R.; KILLINGSWORTH, R. E. How the built environment affects physical activity: views from urban planning. American Journal of Preventive Medicine, v. 23, n. 2, p. 64-73, 2002.

HOLLAND, J. H. Adaptation in natural and artificial systems: an introductory analysis with applications to biology, control, and artificial intelligence. University of Michigan Press, 1992.

IBGE - Instituto Brasileiro de Geografia e Estatística. Censo Demográfico 2010: Microdados da pesquisa. Disponível em: https://censo2010.ibge.gov.br/resultados.html. Acesso em: 16 jun. 2019.

IPEA - Instituto de Pesquisa Econômica Aplicada. Desafios da mobilidade urbana no Brasil. Texto para Discussão, 2016. Disponível em: http://www.ipea.gov.br/. Acesso em: 16 mar. 2019.

JUNEJA, S. S.; SARASWAT, P.; SINGH, K.; SHARMA, J.; MAJUMDAR, R.; CHOWDHARY, S. Travelling Salesman Problem Optimization Using Genetic Algorithm. In 2019 Amity International Conference on Artificial Intelligence (AICAI), p. 264-268.

KAMARGIANNI, M.; LI, W.; MATYAS, M.; SCHÄFER, A. A critical review of new mobility services for urban transport. Transportation Research Procedia, v. 14, p. 3294-3303, 2016.

KARAKATIČ, S.; PODGORELEC, V. A survey of genetic algorithms for solving multi depot vehicle routing problem. Applied Soft Computing, v. 27, p. 519-532, 2015.

LAPORTE, G. The vehicle routing problem: An overview of exact and approximate algorithms. European Journal of Operational Research, v. 59, n. 3, p. 345-358, 1992.

MÄKINEN, K.; KIVIMAA, P.; HELMINEN, V. Path creation for urban mobility transitions: Linking aspects of urban form to transport policy analysis. Management of Environmental Quality. An International Journal, v. 26, n. 4, p. 485-504, 2015.

MARTORELLI, M.; COSTA, A. G. V.; SÁ, A. C. B. A inclusão do transporte de cargas no sistema nacional de mobilidade urbana. Revista LOGS: Logística e Operações Globais Sustentáveis, v. 1, n. 1, p. 182-197, 2019.

MURRAY, C. C.; CHU, A. G. The flying sidekick traveling salesman problem: Optimization of drone-assisted parcel delivery. Transportation Research Part C: Emerging Technologies, v. 54, p. 86-109, 2015.

OLIVEIRA, L. K.; HENRIQUES, R. S.; OLIVEIRA, R. S.; DENAIS, M. Análise dos benefícios de um espaço logístico urbano na distribuição urbana de mercadorias. Revista Produção Online, v.16, n. 3, p. 988-1006, 2016. 
OSABA, E.; YANG, X. S.; DIAZ, F.; LOPEZ-GARCIA, P.; CARBALLEDO, R. An improved discrete bat algorithm for symmetric and asymmetric traveling salesman problems. Engineering Applications of Artificial Intelligence, v. 48, p. 59-71, 2016.

OYOLA, J.; ARNTZEN, H.; WOODRUFF, D. L. The stochastic vehicle routing problem, a literature review, part I: models. EURO Journal on Transportation and Logistics, v. 7, n. 3, p. 193-221, 2018.

RODRIGUE, J. P.; COMTOIS, C.; SLACK, B. The geography of transport systems. Routledge, 2016.

SCHIFFER, M.; SCHNEIDER, M.; WALTHER, G.; LAPORTE, G. Vehicle Routing and Location Routing with Intermediate Stops: A Review. Transportation Science, v. 53, n. 2, p. 319-343, 2019.

SILVA, J. G. S. Algoritmos de solução para o problema do caixeiro viajante com passageiros e quota. Dissertação (Mestrado em Sistemas e Computação). Programa de Pós-Graduação em Sistemas e Computação, Universidade Federal do Rio Grande do Norte, Natal, Brasil, 2017.

STIGLIC, M.; AGATZ, N.; SAVELSBERGH, M.; GRADISAR, M. Enhancing urban mobility: Integrating ridesharing and public transit. Computers \& Operations Research, v. 90, p. 12-21, 2018.

VARUN KUMAR, S. G.; PANNEERSELVAM, R. A study of crossover operators for genetic algorithms to solve VRP and its variants and new sinusoidal motion crossover operator. International Journal of Computational Intelligence Research, v. 13, n. 7, p. 1717-1733, 2017.

VEENSTRA, M.; ROODBERGEN, K. J.; VIS, I. F.; COELHO, L. C. The pickup and delivery traveling salesman problem with handling costs. European Journal of Operational Research, v. 257, n. 1, p. 118-132, 2017. 